\title{
Estudi i edició de tres versions de La Ventafocs i les germanastres (ATU $480+510$ A) recollides per Adelaida Ferré i Gomis
}

\author{
Laura Villalba Arasa \\ Universitat Rovira i Virgili \\ laura.villalba@urv.cat
}

\begin{abstract}
RESUM
A partir de l'estudi de tres versions del tipus internacional 5IOA, corresponent a la rondalla catalana La Ventafocs i les germanastres, que tenen com a característica comuna el fet d'estar precedides pel tipus ATU 480, La noia caritativa i la germanastra malcarada, en el text de l'article s'estudia la freqüència de la combinació en l'àmbit lingüístic català i en altres àmbits lingüístics que l'hi són propers com ara l'espanyol, el portuguès $i$ el francès, per tal de provar-ne l'eficiència. A partir de l'edició i l'estudi de les tres versions que Adelaida Ferré i Gomis (Barcelona I88I-I955) va recollir en tres poblacions catalanes, s'analitzen les característiques que permeten catalogar-les sota els tipus ATU 480 $+5 I 0 A$ per ampliar, així, el corpus de relats que en l'àmbit lingüístic català combinen aquests dos tipus i que actualment estan llistats en divuit.
\end{abstract}

PARAUles CLAU

rondalla; ATU 5IOA; ATU 480; Adelaida Ferré; combinació

\begin{abstract}
The present article studies three versions of international type 5IOA, corresponding to the Catalan folktale Ventafocs i les germanastres (Cinderella). All three versions share the common characteristic of being preceded by type ATU 480 - The kind and the unkind girls. The article examines the frequency of this combination in the Catalan linguistic area and other nearby language areas such as Spanish, Portuguese and French. The three versions collected by Adelaida Ferré and Gomis (Barcelona I88I-Barcelona I955) in three Catalan towns are analysed to determine their characteristics. As a result they are classified as types ATU 480 and $5 I O A$, thus expanding the corpus of Catalan stories that combine both these types from eighteen to twenty-one stories.
\end{abstract}

KEYWORDS

Folktale; ATU 5IoA; ATU48o; Adelaida Ferré; combination

REBUT: I5.09.2OI5 | ACCEPTAT: OI.IO.2OI5

Estudis de Literatura Oral Popular, núm. 4, 2OI5, I55-I73 | DOI: Io.I7345/elop2OI5I55-I73

ISSN: 2OI4-7996 | http://revistes.urv.cat/index.php/elop 


\section{Introducció ${ }^{1}$}

La Ventafocs i les germanastres, adscrita al tipus 5IOA de l'índex internacional de catalogació (Uther 2004), és una de les rondalles més conegudes i una de les més estudiades a escala internacional. L'argument més conegut a Europa és el de la versió de Charles Perrault, publicada sota el nom «Cendrillon ou La petite pantoufle de verre» a Les Contes de ma mère l'Oye, un recull de vuit contes publicats el I697 sota el títol Histoires ou contes du temps passé, avec des moralités (Alcover 2006: 82). L'altra versió europea àmpliament coneguda és la versió «Ascheputtel» dels germans Grimm recollida en la col-lecció Kinder-und Hausmärchen (I8I2). En territori català la versió publicada més primerenca del relat la trobem en el recull de Manuel Milà i Fontanals «Cuentos infantiles (rondallas) en Cataluña», publicat primer a la «Sección instructiva y amena» de la Gaceta de Barcelona i editat el I853 amb el títol Observaciones sobre la poesía popular, sota el títol «La Cenicienta». Des d'aquest primer títol, en espanyol, en la tradició catalana trobem el relat sota una gran variabilitat de títols, associats bé al nom de la protagonista, habituals en les rondalles mallorquines (Guiscafrè 2008: 238): Joanota, Francisqueta, Na Catalineta..., bé a l'associació del nom amb el motiu de la cendra o, per extensió, amb el foc, el fet de cuidar-lo o atiar-lo: Ventafocs, Bufafocs, Cendrosa, Cendrellosa, Cendrolina.

L'article que segueix s'emmarca en la recerca de la meua tesi doctoral «Adelaida Ferré, folklorista. Edició, catalogació i estudi del seu corpus rondallístic», que va ser defensada a la Universitat Rovira i Virgili el mes d'octubre de l'any $2014 .{ }^{2}$ Un dels principals objectius d'aquesta tesi era el de demostrar com d'important va ser la tasca duta a terme per les dones folkloristes formades pel folklorista català Rossend Serra i Pagès (I863-I929). Per provar d'explicar aquesta realitat desconeguda, i precisament per com d'intensa havia confirmat que havia estat la faena d'aquestes dones, la recerca va centrar-se en una d'aquestes figures femenines: Adelaida Ferré i Gomis (Barcelona I88I-I955). A part d'estudiar-ne la vida i l'obra folklòrica, vaig dedicar un capítol específic a l'edició i a l'estudi d'un corpus de noranta-sis rondalles que va recollir.

Els textos que aquí analitzaré són tres versions de la rondalla de La Ventafocs $i$ les germanastres, que tenen com a característica, específica en aquest corpus però no exclusiva en la tradició, el fet de no ser tipus purs (en aquest cas ATU 5IOA), sinó que són tipus introduïts per l'argument del tipus ATU 480 La germana caritativa i la germana malcarada.

\footnotetext{
I. Aquest article forma part de la investigació del Grup de Recerca Identitats en la Literatura Catalana (GRILC), reconegut i consolidat per la Generalitat de Catalunya (2OI4 SGR 755), i del grup de recerca Identitat Nacional i de Gènere a la Literatura Catalana, del Departament de Filologia Catalana de la Universitat Rovira i Virgili, i s'emmarca en una línia de recerca sobre literatura popular catalana que ha rebut finançament del Ministeri d'Economia i Competitivitat a través del projecte d'R+D FFI20I2-31808.
}

2. Podeu consultar el cos sencer de la tesi a l'adreça web següent: http://hdl.handle. net/Io803/2939Io. 


\section{Els textos}

\subsection{Context i localització}

Adelaida Ferré va recollir noranta-sis rondalles. Aquests textos provenen majoritàriament de dos fons gairebé inèdits conservats a l'Arxiu Històric de la Ciutat de Barcelona: el Fons Personal Rossend Serra i Pagès [FPRSP], que es localitza sota la signatura AHCB3-022/5D.6I ROSSEND SERRA I PAGÈS, i en el Fons Personal Sara Llorens i Carreras [FPSLC], que es localitza sota la signatura AHCB3-308/5D.78 SARA LLORENS I CARRERAS i d'un corpus format per publicacions periòdiques. ${ }^{3}$ Sis de les noranta-sis versions es troben manuscrites en el primer fons, concretament en la carpeta 5D.6I-25/C8 Rondalles catalanes. Setanta-una altres rondalles es localitzen en el Fons Personal Sara Llorens i Carreras en una carpeta independent amb la denominació Rondalles recollides per l'alumna Adelaida Ferré i Gomis. Les dinou rondalles que resten es troben repartides entre les pàgines de diverses publicacions periòdiques del primer terç del segle $\mathrm{xx}$.

De les tres versions que ara analitzo, les dues primeres ( I i II) formen part del corpus de setanta-un altres relats recollits per la folklorista i col-leccionats amb el número 22 FPSLC. La versió III es localitza en la carpeta 5D.6I-25/C8 Novel-lística catalana. Rondalles catalanes del FPRSP.

Es tracta de tres versions manuscrites localitzades a Rubí, la primera; a Alòs de Balaguer, la segona, i a Abella de la Conca, la tercera. De les versions i i II, en podem recuperar la data i la identitat de les informants: Montserrat Cardús (a Rubí, el I9I6) i Maria Mirada (molt probablement a Barcelona, el I907). La identitat de la tercera de les informants no la sabem amb exactitud: una Ventureta d'Abella de la Conca. Malgrat que aquesta rondalla no està datada, sabem que és de I908 o anterior d'acord amb el que s'extreu de la informació de la publicació que Serra i Pagès (I908) fa en l'estudi «Lo fregallot» per al Butlletí del Centre Excursionista de Lleida. Com en la gran majoria del corpus folklòric de Ferré (amb algunes excepcions comptades), les informants són dones i això explica per què la majoria dels materials de Ferré són rondalles, cançons, endevinalles o oracions, gèneres del folklore amb intencions pedagògiques, educatives, moralitzants; gèneres per a infants. En definitiva, uns gèneres que van li interessar pel seu caràcter de pedagoga i la seua formació com a mestra.

\subsection{Edició}

Per a l'establiment dels criteris d'edició de les rondalles que formen el corpus que presento en annex, he tingut en compte els criteris que estableixen altres obres que transcriuen materials folklòrics inèdits i anteriors a la normalització lingüística establerta per Pompeu Fabra. Atès que es tracta de textos recollits de la tradició

3. Els materials analitzats són fruit de la tasca de buidatge i anàlisi d'una sèrie de capçaleres de premsa catalana duta a terme en la segona fase de l'ambiciós projecte interuniversitari Repertori Biobibliogràfic de la Literatura Popular Catalana, que va centrar la seua atenció a estudiar la presència de la literatura popular catalana en les publicacions corresponents al període comprès entre el I894 i el I953, any de la mort del folklorista Joan Amades. Del total de revistes analitzades per a aquesta esmentada fase he analitzat material folklòric de divuit revistes, ja que és aquest el nombre de periòdics que contenen documents aportats per dones. 
oral, he optat per aplicar un criteri al més conservador possible amb aquesta llengua oral perquè es facen paleses les característiques tant dialectals com de registre dels textos. Així, i amb una sèrie d'excepcions, regularitzo l'ortografia dels textos segons la normativa catalana vigent si aquest fet no implica ni pot provocar canvis en una lectura del text en veu alta. ${ }^{4}$

Per a la presentació dels textos faig anar la mateixa forma que he utilitzat en la presentació del corpus textual de la meua tesi doctoral. Això és:

\section{NÚMERO DEL TIPUS}

I. Número de la versió

Títol d'Adelaida Ferré i Gomis / [Títol assignat per mi]

Transcripció del text.

Referència formal de la rondalla:

(i) Número de referència al Fons Personal Rossend Serra i Pagès [FPRSP] de l'Arxiu Històric de la Ciutat de Barcelona | Informant | Localització | Data de recollida |

(ii) Número de referència (assignat per mi mateixa) al Fons Personal Sara Llorens i Carreras [FPSLC] | Informant | Localització | Data de recollida |

$$
\text { *** }
$$

(I) Rondalles catalogades segons ATU: Títol del tipus ATU (Uther 2004) | Títol català del tipus segons Oriol/Pujol (2003, 2008) | Altres possibles catalogacions

(2) Rondalles catalogades al web RondCat (i no a ATU): Títol del tipus «C» | Altres possibles catalogacions.

(3) Rondalles no catalogades

Мот. Motius de la versió segons l'índex de Thompson.

Tal com explicito en el corpus del meu treball de doctorat (Villalba 20I4: 227):

He pres com a model formal l'edició del corpus narratiu folklòric d'Emili Samper (2013) en la seua tesi doctoral que, a la vegada, ell va prendre de l'edició d'El rondallari Aguiló de Jaume Guiscafrè (2008). Totes dues edicions mereixen ésser preses com a models formals d'edició de corpus rondallístics per la claredat en la presentació dels materials. Per això les he tingudes en compte tot i que he adaptat el model a les característiques particulars dels textos que he estudiat.

En el cas d'aquestes tres versions, però, només hi faig constar la primera part de la presentació dels textos, atès que la segona fa referència a la informació catalogràfica i d'estudi i els textos, aquí, tots s'aixopluguen sota la mateixa classificació: 480 + 5IOA.

4. Per a una lectura més aprofundida sobre l'edició de les rondalles de Ferré vegeu l'article «El procés de transcripció, edició i fixació d'un corpus inèdit a partir dels materials rondallístics d'Adelaida Ferré i Gomis» (Villalba 2OI5). 


\section{La combinació ATU $480+510$ A}

Aquestes tres versions responen, com he apuntat més amunt, a la catalogació ATU 480 + ATU 5IOA, una combinació de tipus altament freqüent, de la qual donen compte els estudis d'Anna Brigitta Rooth (I95I) o W. E. Roberts (I994). Les tres rondalles presenten una mateixa estructura en què ATU 480 (The Kind and Unkind Girls / La germana caritativa i la germana malcarada) actua d'episodi introductori, molt extens, a ATU 5IOA.

La darrera revisió de l'índex tipològic d'Uther (2004) inclou informació sobre les combinacions de tipus. Per a Carme Oriol (2009), aquestes combinacions entre arguments que ella anomena «compatibles» subratllen la creativitat dels narradors, els quals adapten i estenen els arguments de les rondalles d'acord amb el públic que les escolta. Per tant, la combinació de tipus és molt freqüent, tot i que per ser eficient és necessària aquesta compatibilitat entre els arguments dels elements combinats. Això és, precisament, el que s'esdevé en aquestes tres primeres versions. Pel que fa a la combinació ATU 480 + ATU 5IOA, la confluència entre els dos tipus és elevada. Ho és no solament en l'àrea lingüística catalana, en què dels quaranta relats que documenten Oriol/Pujol sota el tipus 5IOA, vint-i-un són combinacions d'aquest tipus rondallístic amb altres tipus i, d'aquestes, en divuit la combinació és ATU 480 + ATU 5IOA, sinó també en les tres àrees lingüístiques i de tradicions més properes.

En l'àmbit francès Paul Delarue i Marie-Louise Tenèze (I964: 245-255) enumeren trenta-vuit versions de tipus rondallístic 5IOA d'ATU, de les quals se'n troben deu de combinades amb el tipus ATU 480. Delarue-Tenèze indiquen que aquesta combinació és freqüent entre les versions franceses.

En l'àmbit hispanoportuguès, d'una banda, en l'àrea lingüística de l'espanyol, i tenint en compte la descripció de Julio Camarena i Maxime Chevalier (I995: 408-4I3), hi ha constància de dinou versions del tipus 5IOA, deu de les quals inclouen la combinació ATU 480 + ATU 5IOA. De les nou restants, cinc responen al tipus d'ATU 5IOA pur i quatre a altres combinacions de tipus; d'altra banda, de les vint-i-sis versions portugueses, Cardigos (2006) documenta la combinació d'ATU 5IOA amb ATU 480 en vuit ocasions.

Així, amb les dades a la mà, doncs, observem que el número ATU es combina tot sovint amb altres $\mathrm{i}$, especialment, tal com indica Uther (2004: 294), amb els tipus 327A, 4O3, 480, 5IOB i també amb 408, 409, 43I, 45O, 5II, 5IIA, 707 i 923.

Alan Dundes, al pròleg de l'edició de l'obra de Roberts (I994: ix), afirma que el conte tipus ATU 480 és una de les rondalles més conegudes del món. El seu argument és, en essència, el següent: dues xiques es troben amb una figura donant. La primera la tracta amb amabilitat i és premiada en conseqüència, mentre que la segona s'hi mostra desagradable i, per tant, és castigada. En general, aquesta rondalla no acostuma a acabar amb el matrimoni de la protagonista bona tal com, segons Propp, marca l'estàndard en les rondalles indoeuropees i això explicaria, doncs, per què aquest tipus sovint es combina amb altres tipus rondallístics. Per a Dundes (Roberts I994: xii) el tipus ATU 480 consisteix en una preparació per al matrimoni més que no pas en la seua consecució. Tot i així, tant Roberts a l'edició del 1958 com Uther a la darrera revisió de l'índex internacional de catalogació inclouen el casament de l'heroïna amb el príncep com un dels acabaments possibles de la rondalla. Consegüentment, però, segueix Dundes, l'argument genèric 
d'aquesta rondalla fa que el tipus ATU 480 siga una introducció molt apropiada per a altres rondalles, per exemple ATU 709, com veurem més avall i La Ventafocs i les germanastres (ATU 5IOA), que sí que es clouen amb el matrimoni de la protagonista. I és això precisament el que s'observa en aquestes tres versions recollides per Ferré.

És en la part introductòria on més es dóna la comunió entre els dos tipus combinats: dues filles, una caritativa i una malcarada (motiu Q2 de Thompson); una madrastra (motiu S3 I de Thompson) o una fillastra com a heroïna (motiu L55 de Thompson). Per tant, aquest podria ser un del motius pels quals és tan freqüent aquesta combinació, tot i que no l'únic. És a dir, no seria estrany que, a partir dels elements propers - introductoris i altres- els arguments dels dos tipus s'haguessen amalgamat.

\subsection{Anàlisi de les versions}

Paul Delarue (I964: I88-I99) divideix el tipus 480 en quatre episodis: I. Les protagonistes, II. La trobada, III. La donació i IV. L'episodi final. En aquestes versions estudiades, el primer episodi funciona com una introducció en la qual es presenten els personatges: un viudo, una madrastra, una fillastra caritativa i bondadosa i una filla malcarada (protagonistes i situacions compartits amb ATU 5IOA), i el naixement del conflicte: la madrastra es casa amb el viudo després que la futura fillastra l'haja persuadit, com en la versió I, induïda per una promesa (no complida) o, simplement, la madrastra es casa amb el viudo, com en les versions II i III. A partir del casament, la fillastra caritativa és maltractada per la madrastra, que li encomana tasques difícils (filar, rentar intestins d'animals...) i l'amenaça amb càstigs severs si no les realitza, tal com passa a $5 \mathrm{IOA}$.

En aquestes tres versions, l'episodi en què la noia bondadosa es troba en una situació injusta i ha de realitzar unes determinades tasques, que correspon al segon episodi de Delarue-Tenèze, és molt més extens que habitualment i s'amplia, precisament, per intensificar i emfasitzar aquest tracte injust. A més, aquest èmfasi es veu reforçat gràcies al mecanisme de la iteració a través de fórmules rimades que es van repetint i encadenant, amb la qual cosa es compleix la segona de les lleis de la narrativa oral formulades per Axel Olrik (I992), que és la llei de la repetició. D'altra banda, tant en el tipus 480 com en el 5IOA l'heroïna bondadosa, i en aquest punt comença el segon episodi, pot dur a terme les tasques encomanades gràcies a l'ajuda d'un donant (en aquest cas, la Mare de Déu sota l'aparença d'una vella), que també li fa un encàrrec (en aquest cas, que li mire el cap).

En el tercer episodi, La donació, la fillastra caritativa es mostra amable i bondadosa amb el donant i accepta de grat fer allò que li demana: li mira el cap i diu que l'hi veu coses bones (or i plata o ametles i avellanes) o fa una tria modesta. Gràcies al seu bon comportament (o a la seua humilitat), la noia caritativa rep un premi. En les tres versions aquest premi és un estel al front que rep després d'haver atès el consell del donant (no girar-se quan séntiga un burro bramar i girar-se quan séntiga una campaneta sonar).

Segons W. E. Roberts, el motiu de l'estel al front (F545.2.I de Thompson) és el premi més comú al sud d'Europa, ja que apareix en trenta-quatre versions d'aquesta àrea geogràfica $\mathrm{i}$, a pesar que altres premis (gemmes i similars caent de la boca de la protagonista o or i similars caent del seu cabell) hi són també molt 
freqüents, l'estel al front bé podria ser el premi original del tipus. En les tres versions estudiades, l'estel al front realça la bellesa de la protagonista i permet associar la seua bellesa física amb la bellesa interior (la bondat).

Només en una de les tres versions (la II), la Mare de Déu, en lloc de demanar a l'heroïna que li mire el cap, li mostra una capsa de vestits perquè en trie un. La noia tria el més lleig per humilitat i llavors la donant li regala el més bonic. En la versió III la donant ofereix una ametla i una avellana màgiques a l'heroïna, elements propis del tipus 5IOA. Per tant, aquest és un altre factor que propicia la compatibilitat entre els dos arguments. En les mateixes circumstàncies que acabo de descriure la germana o germanastra malcarada es mostra desagradable amb la figura donant, li respon malament, dient que al cap hi veu «polls i caparres», i rep un càstig: en els tres casos una cua d'ase al front, que la fa encara més lletja.

A partir d'aquí, hi ha un trencament amb el tipus 480 i comença, tal com he dit que preveuen la majoria dels estudis, La Ventafocs i les germanastres, adscrita en el tipus 5IOA de l'índex internacional de catalogació (Uther 2004).

L'argument de la rondalla, amb les especificitats d'aquestes versions, és el següent: l'heroïna és obligada per la seua madrastra a realitzar les tasques domèstiques més feixugues (agranar, escurar, filar, però en cap d'aquestes tres versions s'hi troba una tasca associada a la cendra o al foc, com sí que passa en les més estereotipades i que sovint dóna el nom a la protagonista). Com he comentat, aquest és un element comú amb ATU 480.

A partir d'aquí, les seues germanastres es burlen d'ella i la deixen tancada a casa (o en una cambra, o a la pastera, com en la versió I). L'heroïna és auxiliada per un ésser sobrenatural (en aquestes tres versions, com ja he dit, la Mare de Déu) que canvia el seu aspecte de criada pel d'una noia molt bella amb l'ajuda d'elements màgics; en aquest cas, fruits que proporcionen abillaments preciosos (en la versió III aquests fruits que constitueixen els motius D985.3 i D985 de Thompson els els proporciona en el desenvolupament de $480 \mathrm{i}$, per tant, aquest fet reforça, de nou, la unió entre els dos tipus).

L'heroïna, un cop abillada, assisteix al ball que organitza el príncep a palau, ningú no la reconeix i el príncep se n'enamora. (En una de les tres versions d'Adelaida Ferré, la I, l'episodi de l'enamorament no té lloc en el ball, com en les versions més conegudes, sinó que es produeix durant una missa i, per tant, l'escenari no és un palau, sinó una església.) En aquest punt, la noia fuig del ball de forma precipitada i el príncep no pot atrapar-la. En la fugida la noia perd una sabata (no en la versió I) que troba el príncep. Aquest fa emprovar la sabata (H36.I) a totes les noies del regne fins que encaixa en el peu de l'heroïna. En algunes versions, com passa en la II, l'episodi final va seguit del motiu $\mathrm{S}_{432}$ de Thompson, que és la substitució de l'heroïna tan característica d'ATU 403 The Black and the White Bride, un tipus que comença com 480 i com 5IOA: una madrastra que estima la filla i odia la fillastra en desmesura. Per tant, un altre tipus altament compatible, tal com indica Uther (2004: 294), amb els dos que he analitzat i que, en cas d'haver-li convingut, sembla que la narradora de la rondalla hauria cosit sense cap mena de problema i l'hauria allargat encara més.

Si seguim l'anàlisi dels elements del tipus que proposen Delarue-Tenèze (I964: 248-250), observem com aquestes tres versions s'hi adapten prou bé. Així: 
Versió I: \{480 I. Les héroïnes A. Les héroïnes du conte sont deux demi-sœurs B. La fille laide et méchante est cajolée; BI: per sa marâtre II. Les rencontres A. La mère (marâtre) envoie la bonne fille; A2: porter quelque chose au ruisseau; C. Ella rencontre; C8: la Ste Vierge; C9: sous l'apparence d'une vieille femme; CI3: qui lui demande; CI8: à être coiffée(s) ou pouillée(s) III. Les dons A. La bonne fille se montre aimable; AI: en répondant poliment; $\mathrm{A}_{5}$ : en acceptant de coiffer ou de pouiller sa tête; A6: et en disant y trouver or et argent; B: elle obtient les récompenses suivantes; $\mathrm{B}_{3}$ : une étoile d'or qui descend sur son front; $\mathrm{B}_{5}$ : une plus grande beauté; C. La méchante fille, dans les mêmes circonstances, se montre désagréable; $\mathrm{C}_{\mathrm{I}}$ : répondant mal; $\mathrm{C}_{4}$ : disant qu'elle trouve "pous et lentes» sur la tête à pouiller D. Elle obtient des dons inverses de sa sour; D3: une queue d'âne ou autre malpropreté qui descend sur son front; D5: une plus grande laideur Iv C. Le conte se continue par le T. 5IOA (Cendrillon)\} I. L'héroïne persécutée CI. L'héroïne est obligée de faire tous les travaux sales; D. L'héroïne est appelée cendrillon, ou d'un nom très voisin II. L'aide magique A. L'héroïne reçoit d'un être secourable; A4: une noisette; A5: une amande; $\mathrm{B}$ : alors que sa demi-soeur va à la messe; B3: l'héroïne doit rester à la maison; $\mathrm{B} 4$ : et accomplir des tâches presqu'impossibles; $\mathrm{B} 7$ : autres tâches; $\mathrm{C}$. L'héroüne est aidée, dans l'accomplissement des tâches imposées par un être secourable; CI: les tâches de l'héroïne sont accomplies en son absence par un être secourable; $\mathrm{C}_{4}$ : qui est la Ste Vierge; D2: l'héroïne trouve dans le(s) fruit(s) reçu(s) D9: autre(s) robes(s) merveilleuse; Dio: et tout un équipage III. La rencontre avec le prince Ar: l'héroïne se rend ainsi parée à la messe, A2: une seule fois; B. Le prince n'a d'yeux que pour l'héroïne; C. Sa sour, ou la marâtre, en rentrant lui parle de la belle inconnue; D9: les beaux atours de l'héroïne disparaissent, et elle rentre en haillons iv. Preuve et mariage D. La marâtre essaie de substituer sa fille à l'héroïne; DI: mais un petit chien (gat) dénonce la supercherie E: heureux mariage.

Versió II: \{480 I. Les héroïnes A. Les héroïnes du conte sont deux demi-sœurs; B. La filles laide et méchante est cajolée; BI: per sa marâtre II. Les rencontres A. La mère (marâtre) envoie la bonne fille; A2: porter quelque chose au ruisseau; C. Elle rencontre; C2: sur les bord de la rivière; C8: la Ste Vierge; C9: sous l'apparence d'une vieille femme III. Les dons A. La bonne fille se montre aimable; Ar: en répondant poliment; Aıo: en faisant des choix modestes; B: elle obtient les récompenses suivantes; B3: une étoile d'or qui descend sur son front; $\mathrm{B}_{5}$ : une plus grande beauté; B9: en réponse à son choix modeste; Bıo: la plus belle robe; BI8: et que son travail soit accompli; C. La méchante fille, dans les mêmes circonstances, se montre désagréable; C6: choisissant pour elle toujours le meilleur; D. Elle obtient des dons inverses de sa sœur; D3: une queue d'âne ou autre malpropreté qui descend sur son front; D5: une plus grande laideur; D8: en réponse à son choix immodeste, des cadeaux de sa punition IV Episode final C. Le conte se continue par le T. 5IOA (Cendrillon)\} I. L'héroïne persécutée CI. L'héroïne est obligée de faire tous les travaux sales; D. L'héroïne est appelée cendrillon, ou d'un nom très voisin II. A. L'héroïne reçoit d'un être secourable; A7: alors que l'héroïne n'avait rien voulu demander; B. Alors que ses (sa) demi-sœur(s) vont (va) au bal; B3: l'héroïne doit rester à la maison; B4: et accomplir des tâches presqu'impossibles; B7: autres tâches; CI: les tâches de l'héroïne sont accomplies en son absence par un être secourable; C4: qui est la Ste Vierge II. La rencontrée avec le prince A: L'héroïne se rend ainsi parée au bal; A2: une seule fois; B: le prince n'a d'yeux que pour l'héroïne; C: sa sour, ou la marâtre, en rentrant lui parle de la belle inconnue; $\mathrm{C}_{3}$ : l'héroïne répond qu'elle est bien heureuse, mais qu'elle-même ne peut rien voir puisqu'elle ne sort jamais; D: S'étant attardée; 
D2: l'héroïne perd en s'enfuyant; D4: une pantoufle; D8: qui est ramassée par le prince; D9: les beaux atours de l'héroïne disparaissent, et elle rentre en haillons Iv. Preuve et mariage A. Le prince décide de m'épouser que celle à qui ira la pantoufle; C: en dépit des récriminations de ses sœurs; $\mathrm{C}_{4}$ : car elle va mettre ses beaux habits; D: La marâtre essaie de substituer sa fille à l'hérö̈ne; Dr: mais un petit chien dénonce la supercherie; $\mathrm{E}$ : Heureux mariage.

Versió III: \{480 I. Les héroïnes A. Les héroïnes du conte sont deux demi-sœurs; B. La filles laide et méchante est cajolée; BI: per sa marâtre II. Les rencontres A. La mère (marâtre) envoie la bonne fille; A2: porter quelque chose au ruisseau; C. Ella rencontre; C2: sur les bord de la rivière; C9: sous l'apparence d'une vieille fermme, Ci3: qui lui demande; CI8: a être coiffée(s) ou pouillée(s) III. Les dons A. La bonne fille se montre aimable; AI: en répondant poliment; A5: en acceptant de coiffer ou de pouiller sa (leur) tête; B: elle obtient les récompenses suivantes; B3: une étoile d'or qui descend sur son front; B5: une plus grande beauté; C. La méchante fille, dans les mêmes circonstances, se montre désagréable; $\mathrm{C}$ : répondant mal; $\mathrm{C}_{4}$ : disant qu'elle trouve "pous et lentes» sur la tête à pouiller; D. Elle obtient des dons inverses de sa soeur; D3: una queue d'âne ou autre mapropeté qui descend sur son front; D5: une plus grande laideur Iv Episode final C. Le conte se continue par le T. 5IOA (Cendrillon)\} I. L'héroïne persécutée CI. L'héroïne est obligée de faire tous les travaux sales II. L'aide magique A. L'héroïne reçoit d'un être secourable; A4: une noisette; A5: une amande; D2: l'héroïne trouve dans le(s) fruit(s) reçu(s); D9: autre(s) robes(s) merveilleuse III. La rencontre avec le prince A: l'héroïne se rend ainsi parée au bal; A3: a deux reprises; B: le prince n'a d'yeux que pour l'héroïne; $\mathrm{B}$ : et ne danse qu'avec elle; $\mathrm{B} 2$ : mais elle doit être rentrée avant une heure déterminée; C. Sa sœur, ou la marâtre, en rentrant lui parle de la belle inconnue; C3: l'héroïne répond qu'elle est bien heureuse, mais qu'elle-même ne peut rien voir puisqu'elle ne sort jamais; D9: les beaux atours de l'héroïne disparaissent, et elle rentre en haillons Iv. Preuve et mariage A. Le prince décide de n'épouser que celle à qui ira la chaussure (pantoufle); A2: et la fait essayer à toutes les jeunes filles du royaume; C. En dépit des récriminations de ses sœurs; C2: l'héroüne est conviée à essayer également la chaussure, qui s'adapte parfaitement à son pied, et est reconnue E. Heureux mariage.

\section{Conclusions}

Aquest article dóna mostra de l'elevada freqüència amb què la combinació 480+5IoA es dóna en l'àrea romànica. Observant les característiques de les tres versions d'Adelaida Ferré i, sobretot, tenint en compte el tant per cent tan elevat amb què aquesta combinació es dóna també entre els relats de la folklorista, podem reafirmar la idea que aquesta combinació es trobava en l'imaginari popular i que els narradors eren capaços de reproduir-ne els arguments com un tot pel fet que, com he anat repetint, es tracta de tipus altament compatibles i que, per tant, faciliten la creativitat en els narradors. Aquesta combinació en concret es dóna perquè tant un tipus com l'altre comparteixen elements comuns que plantegen una mateixa problemàtica: el tractament injust que rep la protagonista per part de la seva madrastra en l'etapa prèvia al matrimoni.

Adelaida Ferré era folklorista, però també era mare, i era mestra; tenia una voluntat pedagògica que li venia, molt probablement de la formació que havia rebut del mestre Serra i Pagès. Possiblement el seu repertori de rondalles està condicio- 
nat per l'interès a recollir relats que, com aquest, presenten un contingut en què es fa evident la funció formativa de la rondalla. Aquí, 480 constitueix el pas de la infantesa al món adult, en aquest cas explicant la rivalitat entre germans, la moralitat del bon comportament i, arribada la criatura al món adult preparada per al matrimoni, objectiu principal que marcava la trajectòria vital de les dones catalanes de principis del segle xx, el matrimoni; l'episodi final de 5IOA és la recompensa per a l'heroïna, els atributs de la qual es destaquen i s'equilibren (bondat interior amb bondat exterior o bellesa) en l'episodi, ampliat i estès a 480 i repetit a 5 IOA, de les tasques encomanades.

Amb l'anàlisi d'aquests tres textos, s'augmenta el tant per cert de relats que en l'àmbit català tenen aquesta combinació i es reforça la hipòtesi, tant de Warren E. Roberts com d'Anna Brigita Rooth, que aquesta combinació és característica, sobretot, de la zona sud del continent europeu.

\section{Referències bibliogràfiques}

Alcover, Antoni M. (2006): Aplec de Rondaies Mallorquines d'En Jordi d'es Racó. Mallorca: Editorial Moll.

Camarena laucirica, Julio; Maxime Chevalier (I995): Catálogo tipológico del cuento folklórico español. Cuentos maravillosos. Madrid: Gredos.

CARDigos, Isabel (2006): Catalogue of Portuguese Folktales. With the collaboration of Paulo Correia i J. J. Diaz Marques. Folklore Fellows' Communications 29I. Hèlsinki: Suomalainen Tiedeakatemia.

Delarue, Paul; Marie-Louise Tenèze (I964): Le conte populaire français. Volum II [Contes merveilleux, deuxième partie]. París: Éditions Maisonneuve et Larose.

GUISCAFRÈ, Jaume (2008): El rondallari Aguiló: transcripció, catalogació i estudi introductori. Barcelona: Publicacions de l'Abadia de Montserrat.

OlRIK, Axel (1992): Principles for Oral Narrative Research. Bloomington: Indiana University Press.

ORIOL, Carme (2009): «Thumbling (ATU 700), a Folktale From Early Childhood». Dins Rolf Wilhelm BREDNICH (ed.): Erzählkultur. Beiträge zur Kulturwissenschaftlichen Erzählforschung. Berlín: Walter de Gruyter, p. 223-244.

ORIOL Carme; Josep Maria PUJOL (2003): Índex tipològic de la rondalla catalana. Barcelona: Generalitat de Catalunya.

- (2008): Index of Catalan Folktales. Folklore Fellows' Communications 294. Hèlsinki: Suomalainen Tiedeakatemia.

Rooth, Anna Birgitta (I95I): The Cinderella Cycle. Lund: CWK Gleerup.

Roberts, Warren E. (I994): The Tale of the Kind and the Unkind Girls: AaTh 480 and Related Tales. Detroit: Wayne State University Press.

SAMPER, Emili (20I3): «Cels Gomis i Mestre: Biografia i narrativa folklòrica». Tesi doctoral dirigida per la Dra. Carme Oriol i Carazo i el Dr. Magí Sunyer i Molné. Tarragona: Departament de Filologia Catalana de la Universitat Rovira i Virgili.

SERra i PAGÈs, Rossend (i908): “Lo Fregallot”. Rondalla». Butlletí del Centre Excursionista de Lleida I, núm. 9 (I de setembre, I908): I-6. 
UTHER, Hans-Jörg (2004) [ATU]: The Types of International Folktales. A Classification and Bibliography. Based on the System of Antti Aarne and Stith Thompson. Folklore Fellows' Comunications 284, 285, 286. Hèlsinki: Suomalainen Tiedeakatemia.

VILALbA ArASA, Laura (2OI4): «Adelaida Ferré i Gomis, folklorista. Edició, catalogació i estudi del seu corpus rondallístic». Tesi doctoral dirigida per la Dra. Carme Oriol Carazo i codirigida per la Dra. Montserrat Palau Vergés. Tarragona: Departament de Filologia Catalana de la Universitat Rovira i Virgili.

- (20I5): «El procés de transcripció, edició i fixació d'un corpus inèdit a partir dels materials rondallístics d'Adelaida Ferré i Gomis». Dins Àngel VerGÉs; Vicent VIDAL (eds.): Etnopoètica: arxius i materials inèdits. Alacant: Grup d'Estudis Etnopoètics de la Societat Catalana de Llengua i Literatura, filial de l'Institut d'Estudis Catalans, p.2II-229.

\section{Annexos}

La fregallot

Una vegada ere una mestra que tenie una filla, i a costura diu que hi anave una nena que tenie lo pare molt guapo, i la mestra li va dir que si a cas lo seu pare tenia intenció de casar-se i es casés amb ella, a la nena la farie anar molt guapa i l'estimarie molt.

-Ja l'hi diré doncs, ja faré els possibles perquè es pogueu casar amb ell.

I tant i tant va fer, que per últim se van casar i a la filla d'ell la feien anar molt malament i la posaven sota la taula i recollive els ossos i lo que ells no volien.

Un dissabte la madrastra va matar un be i les tripes no les van llençar. Diu:

-Ja les anirà a rentar aquell fregallot.

I li va dir:

—Cuidado que no t'escapen perquè si t'escapen te castigaré molt.

I aixís que va ser al riu li van escapar i ella molt desesperada, riu avall veiam si les agafava, i aixís que va ser un trosset avall, va trobar un cavador i li va dir:

-Cavador, el bon cavador,

Déu vos do bona cavada.

¿No hauriu vist passar un budellim-budellam

que per l'aigua anave baixant?

-Ai no, xiqueta. Aquí baix trobaràs un fangador que poder l'haurà vist.

Quan lo troba li diu:

-Fangador, el bon fangador,

Déu vos do bona fangada.

¿Hauriu vist passar un budellim-budellam

que per l'aigua anave baixant? 
-Ai no, xiqueta. Aquí baix trobaràs un llaurador que poder l'haurà vist.

Diu:

-Llaurador, el bon llaurador,

Déu vos do bona llaurada.

¿Hauriu vist un budellim-budellam

que per l'aigua anave baixant?

-Ai no, xiqueta. Aquí baix trobaràs un vellet que poder l'haurà vist.

Lo vellet era Nostre Senyor i ella li diu:

-Vellet, lo bon vellet,

Déu vos do bona vellesa.

¿Hauriu vist un budellim-budellam

que per l'aigua anave baixant?

-Ai no, xiqueta. Aquí baix trobaràs una velleta que poder l'haurà vist.

Troba la velleta, que era la Mare de Déu, i li diu:

-Velleta, bona velleta,

Déu vos do bona vellesa.

¿Hauriu vist passar un budellim, budellam

que per l'aigua anave baixant?

-Mira'm lo cap, què m'hi trobes.

-Or i plata.

-Or i plata seràs tu.

Li va dar lo budellim-budellam i li va dir:

-Ara agafa aquet camí i te'n vas cap amunt. Quan sentis bramar un ruc, no et giris; quan sentis tocar la trincoleta, llavores sí, gira't.

Quan va sentir la trincoleta es va girar i la Verge li va donar l'estel del dia al front, i si ja ere prou guapa, encara ho va ser més.

Quan va arribar a casa seva va dir:

-M'han escapat les tripes.

I la filla de la madrastra li va dir:

- ¿I a on has anat a buscar-les, que t'has tornat aixís?

Llavons ella li va explicar i l'atra també va voler anar-hi per tornar-se tan maca com la seva germanastra.

Se'n va i, quan arriba al riu, deixa anar les tripes expressament riu avall.

Llavons troba el cavador i li diu:

-Cavador, el mal cavador,

Déu vos do mala cavada.

¿Hauriu vist un budellim-budellam

que per l'aigua anave baixant?

—Si vinc te daré un cop d'aixada. 
Se'n va més avall i troba el fangador.

-Fangador, el mal fangador,

Déu vos do mala fangada.

¿Hauriu vist un budellim-budellam

que per l'aigua anave baixant?

- Si vinc te daré un cop de fanga.

Troba el llaurador i li diu:

-Llaurador, el mal llaurador,

Déu vos do mala llaurada.

¿Hauriu vist passar un budellim-budellam

que per l'aigua anave baixant?

—Si vinc te daré un cop de rella.

Troba el vellet i li diu:

-Vellot, lo mal vellot,

Déu vos do mala vellesa.

¿Hauriu vist passar un budellim-budellam

que per l'aigua anave baixant?

-Mira, aquí baix trobaràs una velleta.

- Vellota, mala vellota,

Déu vos do mala vellesa.

¿Hauriu vist passar un budellim-budellam

que per l'aigua anave baixant?

-Mira'm lo cap, què m'hi trobes.

-Xinxes, polls i quibarres. ${ }^{5}$

-Mira, ara te'n vas cap amunt i quan sentis bramar lo ruc, te tombes.

Quan va sentir bramar lo ruc se va tombar i la Verge li va donar la cua del ruc al front i, si lletja ere, més lletja va ser.

Quan va arribar a casa, sa mare:

- ¿Com t'has tornat?

-Aquet fregallot me deu haver enganyat, que ella es va tornar maca i jo lletja.

Diu que quan anave a missa ere la riota de tot lo poble i a l'atra la deixaven a casa i li deien:

-Fregallot: 'grana, escura i vés a l'hort.

I així que elles eren fora se li apareixie la Verge i li deie:

-Vés a missa.

— ¡Oh! ¡Si he de fer tot això!

5. A pesar que cap diccionari no recull aquest mot, resulta evident que és una variant de caparra (cf. la forma xibarra registrada pel DCVB al Pallars, la Ribagorça i Tremp i, més avall en aquest corpus de rondalles, les variants pitarra i quiparra). 
- No t'amoïnis. Vés a missa i posa't al costat de la teva germanastra, i quan vindràs ja ho trobaràs tot fet.

I li va dar una 'vellaneta, una castanyeta i una tarongeta.

Ella va trencar la 'vellaneta i li va sortir un vestit de seda molt maco; va trencar la castanyeta i li van sortir unes sabates, i per últim va obrir la tarongeta i li va sortir una mantellina.

Va mudar-se, se'n va anar a missa i es va posar al c-ostat de la seva germanastra, que diu que tota la missa se la va estar mirant i deia:

— ¡Ai que és guapa! ¡No n’hi ha cap més en tota l’iglésia com aquesta!

Quan va sortir (que va ser la primera), lo fill del rei se'n va enamorar i la va seguir per fer-se-la demanar.

Quan hi van arribar la madrastra i sa filla, ella ja tornava a anar mal vestida i elles li deien: pa...!

— ¡Ai, Fregallot! Si haguesses vingut a missa haurís vist una senyora ¡més gua-

-Poder sí,

poder no,

poder ere jo.

— ¿Què deu volguer ser aquet fregallot?

I això diu que va durar tres dies i elles ja pensaven:

-Poder sí que ho és, però trobem tota la feina feta: ¿com pot ser?

L'endemà s'hi presenta lo rei per demanar-la i va preguntar si hi haví una noia molt maca.

La madrastra li ensenye la seva filla i el rei diu:

-L'atra, vull jo.

-No en tenim cap més que aquesta (a la guapa l'haví fet amagar sota la pastera) i mentres deie això, lo gat que diu:

-Marramiu-marrameu;

l'estel del dia, sota la pastera jeu.

La madastra vinga a dar-li cops de peu an el gat:

—iJa callaràs!

Lo rei que s'aixeca i diu:

-Anem-ho a veure.

La va trobar sota la pastera, es van casar i van ser molt feliços.

Darrera la porta hi ha un fus que quan filem balla, amén Jesús.

[27 | FPSLC] Maria Mirada, I7 anys, minyona de servei | Alòs de Balaguer | s. 1. | febrer de I907। 
II

[Fregallot]

Una vegada eren un pare i una madrastra. La madrastra tenia una filla i el pare una altra. La madrastra estimava molt a la seva filla i la feia anar a costura, i a la fillastra la va fer anar a rentar tripes a la riera. Vet aquí que li va escapar un budellet i ella anava darrere del budellet plorant i troba un vellet:

-Vellet, per bon vellet,

¿hauríeu vist passar un budellet-budellam

que per l'aigua va passant?

Aquell vellet li va respondre:

-Noia, per bona noia, pregunta-ho an 'quella velleta.

-Velleta, per bona velleta,

¿hauríeu vist passar un budellet-budellam

que per l'aigua va passant?

Diu:

-Sí, noia: aquí el tens ben net i ben blanc.

Treu una capsa de vestits i li va donar a triar, i la noia va prendre el més lleig, i aquesta velleta, que era la Mare de Déu, l’hi pren i li dóna el més maco, i li diu:

—Quan siguis en aquesta pujadeta, si sents bramar el ruc, no et giris, i si sents tocar la campaneta, gira't.

Ella que ho va fer aixís mateix: es va girar quan va sentir a tocar la campaneta i li cau l'estrella del sol al mig del front. I era ¡més maca!

Vet aquí que quan va arribar a casa seva i la van veure tan maca, li van dir:

- ¿Pro què has fet, que ets tan maca?

Ella els va explicar tot lo que li havia passat.

Vet aquí que l'endemà la seva madrastra va fer anar a rentar tripes a la seva filla. Aixís com a la fillastra li va escapar el budell, la filla el va tirar avall.

Vet aquí que també troba un vellet i li diu:

-Vellot, per mal vellot,

¿hauríeu vist un budellot-budellam

que per l'aigua va passant?

-Noia, per mala noia, pregunta-ho an aquella velleta.

-Vellota, per mala vellota,

¿hauríeu vist passar un budellot-budellam

que per l'aigua anava passant?

Diu:

—Té, noia: aquí el tens ben brut i ben negre. 
Li treu una capsa de vestits, que triï el que vulgui. Ella va triar el més maco. Aquesta velleta, que era la Mare de Déu, l’hi pren i li dóna el més lleig, i li diu:

-Quan siguis an aquesta pujadeta, si sents a tocar la campaneta, no et giris; si sents a bramar el ruc, gira't.

Vet aquí que ella ho va fer aixís mateix i li va caure la cua del ruc al mig del front.

Ella se'n va a casa seva i la seva mare quan la veu:

— ¡Reina santíssima! ¡Treu-te això de la cara!

Vet aquí que un dia en aquet poble van fer un gran ball i van anar-hi mare i filla, i a l'altra la van deixar a casa seva i li deien la Fregallot, i li van manar que quan elles tornarien, havia de tenir feta tota la feina de rentar, passar bugada i tenir la roba eixuta.

Ella, plorant, se reclamava ${ }^{6}$ amb la Mare de Déu que no podia fer-ho. La Mare de Déu hi va anar i li va dir:

-Muda't i vés-te'n al ball. (Hi van anar els angelets i li van fer tota la feina.)

Ella se'n va anar al ball. Quan van veure aquella noia tan maca, tothom va quedar esmirat. ${ }^{7}$ El fill del rei se'n va enamorar. Li preguntava d'on era i ella no l'hi va voler dir. Un ball abans de parar, ella se'n va anar.

Pel camí va perdre la xinel-la. Va arribar a casa seva i es va posar del mateix modo que anava sempre: bruta.

Arriba la seva madrastra i li diu: rau. ${ }^{8}$

— ¡Ai, Fregallot! Si haguessis vingut, hagueres vist una noia ¡més maca!, a sa-

-Potser sí, potser no,

potser sí que era jo.

— ¿Què seràs, què seràs, Fregallot?

Aquesta xinel-la la va trobar el fill del rei, que va seguir els passos d'aquesta noia i va veure que es ficava an 'quella casa. Van anar-hi per veure qui havia perdut aquella xinel-la i va baixar la de la cua del ruc, i no li va estar bé. El fill del rei diu:

—Que baixi l'altra noia.

—Tant és que baixi com que no baixi, que no li estarà bé.

-Bueno, que baixi.

La de la cua del ruc puja a dalt, li dóna un vestit seu:

-Fregallot, posa't aquet vestit.

6. El DCVB recull, entre els significats de reclamar-se el de 'comanar-se a algú, invocar-lo' i l'il-lustra amb la cita següent de Serra i Boldú: «la Mare de Déu... són molts los pobles del voltant que acuden a reclamar-s'hi». Tanmateix, en la frase d'aquesta rondalla la noia es reclama amb la Mare de Déu d'una cosa. Això acosta més el significat d'aquest verb a 'queixar-se, plànyer-se', accepció que el DCVB només registra, però com a pròpia de l'eivissenc.

7. Forma dialectal de l'Empordà i Menorca d'admirar.

8. És a dir, al ball. Crida l'atenció la manca d'article, com en les contruccions arcaiques a pagès o a plaça. 
Ella el va prendre, però se'n va anar a mudar-se i es va posar el vestit d'estrelles i una xinel.la.

El rei li emprova la xinel-la i li va estar molt bé, i s'hi va casar.

Vet aquí que quan venien de casar-se, per comptes de pujar al cotxe l'Estrella d'Or, hi puja la Cua de Ruc, que se l'enduguessin cap al palàcio.

El gosset anava darrere i deia:

Guà, guà, guà:

Cua de Burro, Cua de Burro.

Guà, guà, guà:

Cua de Burro en cotxe va

i l'Estrella d'Or a casa està.

Vet aquí que el rei, al sentir que el gosset deia això, va dir-li an ella:

-Alci's el vel, alci's el vel.

I ella li contestava:

- ¿I ara, per què?

El rei li alça el vel i li veu la cua del ruc. Gira el cotxe i se'n va cap a casa a buscar l'Estrella d'Or. Allavòrens el gosset comença:

Guà, guà, guà, Estrella d'Or, Estrella d'Or.

Guà, guà, guà,

Estrella d'Or en cotxe va

i la Cua de Burro a casa està.

Qüento contat, ja està acabat.

[37 | FPSLC] Montserrat Cardús, 24 anys, teixidora de seda | Lavit del Penedès | s. d. | 


\section{Rondalla de la Ventafocs}

Una vegada era una mare que va quedar viuda i es va tornar a casar i el seu marit tenia una noia i ella una altra. Vet aquí que a la del pare la va fer anar a guardar una cabreta i li feia filar llana. La mairasta9 ${ }^{9}$ mai l'hi trobava ben filada. Ella sí que la dóna a filar a la cabreta i li diu:

—Tu em filaràs la llaneta

i jo et faré l'herbeta.

Llavores arriba a casa i quan la mairasta va veure la llana tan ben filada diu:

— ¿Qui te l'ha filada?

-La cabreta.

Aquesta mairasta que hi va fer anar a la seva filla, però la cabreta no l'hi va volguer filar i la va portar a casa molt mal filada.

Ella que sí, que mata la cabra i dóna a la filla del pare els budells perquè els anés a rentar al riu i li diu:

-Pobra de tu que te n'escapi cap perquè o si no et mataré.

Vet aquí que se n'hi va escapar un i ella es posa a córrer riu avall i troba una velleta i li diu:

-Velleta, bona velleta,

¿heu vist passar un budell-budellam

que per l'aigua anava baixant?

-Sí, vine cap aquí.

Llavores li va dar el budell i li va dir:

-Mira'm el cap, ¿què hi trobes?

-Ametlles i avellanes.

-Doncs pren una ametlla i una avellana i quan les trenquis sortiran uns vestits molt macos.

Llavores li va dir que quan sortís el sol s'hi girés ben rodona i de cara. Ella va fer-ho i es va tornar més guapa encara.

Se'n va cap a casa i la mairasta, quan la va veure tan maca i que no li faltava cap budell, li va dir que com havia sigut allò. La noia li va explicar lo que li havia passat.

Vet aquí que mata una altra cabra i hi fa anar la seva filla i li diu:

-Mira, si t'escapa algun budell no cal que t'acostis a casa.

N'hi va escapar un i, corrent per agafar-lo, troba una velleta i li diu:

9. Variant dissimilada de mairastra, que és la forma que pren mad(r)astra en els parlars pirinencs. 
-Vellota, mala vellota

¿heu vist passar un budell-budellam

que per l'aigua anava baixant?

—Sí, vine cap aquí.

Li va dar el budell i li va dir:

-Mira'm el cap, ¿què hi trobes?

-Polls i pitarres. ${ }^{\text {Io }}$

- Mira, quan sentis un burro bramar te gires ben rodona.

Vet aquí que quan va sentir bramar un burro es va girar i la cua del burro li va quedar enganxada al front i encara va ser més lletja.

Se'n va anar a casa plorant i la seva mare la va perdonar i encara van agafar més ràbia a l'altra noia.

Un dia que hi havia ball a la plaça, la mare i la filla se n'hi van anar i a la maca la van deixar tancada al quarto. Ella que va trencar l'avellana i li va sortir un vestit molt bonic. Es vesteix i se'n va a la plaça i el rei va ballar amb ella perquè era la més maca, però ella abans d'acabar-se el ball se'n va anar.

Quan la mairasta i la seva filla van tornar a casa li van dir:

- Si haguessis vingut a la plaça hauries vist quina noia més maca hi havia.

-Potser sí,

potser no,

potser era jo.

-Mentida, que no eres tu, Ventafocs.

L'endemà van tornar mare i filla a la plaça a ballar i a la maca també la van deixar tancada al quarto. Ella que trenca l'ametlla i li surt un vestit allò que es diu ¡preciosíssim! Es vesteix i se’n va a la plaça i també va ballar amb el rei.

Vet aquí que a l'anar-se'n va perdre la sabateta i el rei la va trobar i la va provar a totes les noies del poble dient que a la que vindria aquella sabateta, seria la reina.

Quan van ser a casa d'aquestes noies, surt la lletja i la sabateta li era petita. Llavores el rei diu:

- Jo sé que teniu una altra noia. Feu-la sortir.

-Aquella noia no surt mai de casa i no ha pogut perdre la sabata.

-No hi fa res, ;que surti!

Surt, li emproven la sabata i, com que li va venir bé, es va casar amb el rei.

[FPRSP| 5D.6I-25/C8-3] Ventureta | Abella de la Conca | s. d. |

Io. Caparres (DCVB). 